\title{
Towards a National Innovation System in México Based on Knowledge
}

\author{
Victor Helios Feria, Universidad Politécnica de Valencia, Spain \\ Antonio Hidalgo, Universidad Politécnica de Madrid, Spain
}

\begin{abstract}
In the last years, the research in diverse disciplines has increased the importance of innovation studies at the national level. In this sense, this paper proposes the development of National Innovation Systems (NIS) and its application to the economy in Mexico. Considering the characteristics and limitations of the study region, the mentioned proposal of NIS it is necessary to integrate the study of Knowledge-Based Economies (KBE) approach to study of the different approaches developed about the NIS. In addition, we will analyze the studies about the science, technology and innovation in Mexico, and the availability of these indicators.
\end{abstract}

Keywords: NIS, KBE, México

\section{Introduction}

$\mathrm{T}$ HE GREAT ECONOMIC progress made in recent years in different countries is undoubtedly closely related to the processes of innovation at a national level. Indeed, the current industrialized countries have processes that are focused on the creation of their societies and industries, so that societies and industries are Knowledge-Based Economies (KBE) (OECD, 1996; DTI, 1998). Hence generation of new knowledge, technological progress and innovation are determining factors in economic growth. In this regard, the National Innovation Systems (NIS) act through the introduction of knowledge in the economy (and in society in general); it allows an ideal environment to be generated for the creation of intellectual wealth due to their interactive and cooperative nature. Thus, they greatly contribute to national economies' development. Nevertheless, this requires active learning on the part of the individuals and the organizations that participate in the innovation processes. Therefore, the concepts of knowledge and learning are important in all contributions to the analysis of Innovation Systems (Lundvall, 1992; OECD, 1996). On a national level and, particularly in the most developed economies, the increasing importance of knowledge has meant that the net stock of intangible capital (i.e. education and R\&D) has grown more rapidly than the tangible capital (i.e. buildings, transport, highways and machinery). This has unfortunately not yet happened in the developing economies (Mortensen et al., 1997).

According to this context, the research aims to propose the development of a NIS approach from a knowledge standpoint, aimed at its specific applica- tion to a developing economy such as Mexico. The work is focused on contributing a new perspective to the study of national innovation, as it has integrated the approach of Knowledge-Based Economies (KBE) (OECD, 1996; DTI, 1998; APEC Economic Committee, 2000; World Bank, 2002) with the NIS approach (Freeman, 1987; Lundvall, 1992; Nelson, 1993; Patel and Pavitt, 1994; OECD, 1999), considering the current circumstances in Mexico with regard to the NIS approaches developed to date.

\section{Antecedents}

The importance that knowledge and innovation are acquiring, both in developed countries and in emerging countries, is observed, for example, in the set of OECD countries by the increase in R\&D expenditure between 1995 (2.08) and 2004 (2.26) as percentage of the GDP. The same situation is also repeated in the number of researchers per thousand inhabitants; whereas in 1995 it was $7 \%$, in 2003 it was $8.3 \%$. Another fact that emphasizes the importance of R\&D is the European Union's (EU) recognition that "knowledge and innovation" lie at the heart of economic progress and development of employment in Europe (Hidalgo, 2004).

In Mexico, as result of the R\&D efforts during the last thirty years, and due to the process of restructuring Mexico's economic and social model, it has been possible to construct a S\&T platform (System of Science and Technology) expressed in indicators such as the following: i) public institutions specializing in R\&D, ii) decentralization of S\&T-related activities, iii) formation of long-standing scientific communities, iv) political and public institutions devoted to their coordination and promotion, v) cre- 
ation of different laws in the matter, and vi) legislation to promote private investment in S\&T, among others. Nevertheless, different conclusions are drawn from the observations of diverse studies undertaken, which make it possible to reflect on the reasons why the S\&T system is deficient. For example, although it is observed that there is awareness that $\mathrm{S} \& \mathrm{~T}$ development is an engine for the countries' growth and well-being, there are considerable political weaknesses when instruments are proposed that enable translating the S\&T efforts into the technological modernization of the industrial sector (Casas et al., 2000; CONACYT, 2001). Also, the "North American Free Trade Agreement" (NAFTA) is an opportunity to intensify $\mathrm{S} \& \mathrm{~T}$ relations between Canada, the United States and Mexico (Ratchford, 1991, Wilson 1992), thus, only some specific areas of incidence of NAFTA are recognized in S\&T development, particularly due to the cultural and economic asymmetries of the different scientific communities (Davis, 1991, 1992; Hill and Wonnacott, 1991).

On the other hand, although a National System of Innovation (NIS) does not exist in a formal way in Mexico, from the mid 90s, the National Council of Science and Technology (CONACYT) began its first efforts to tie innovation and knowledge in with economic performance. In 1997, CONACYT issued a document based on the Knowledge and Innovation project (KIP), which points to “... increasing the generation, dissemination and application of knowledge for innovation", in order to achieve the development of the private sector and improve the competitiveness of Mexican industry. Of the above mentioned document there is a diagnosis of the current S\&T situation in Mexico, emphasizing that i) the governmental policies and the institutional framework do not provide the necessary incentives for joint work between research institutions and companies, ii) investment in S\&T is low, iii) demand-oriented institutions of technological support are lacking, iv) companies have low productivity, and v) the Innovation System (IS) inefficiently channels the results of R\&D. In 2001, the results of the first National Survey of Innovation (NSI) performed in Mexico (INEGI and CONACYT, 2001) were presented. Nevertheless, although different conclusions can be drawn from the above-mentioned survey, the regulatory gap and the little experience in achieving said studies mean that they have limited potential due to restricted access to information and, therefore, little dissemination.

In this respect, from an innovation perspective, Mexico shows a performance in terms of innovation that is pertinent for both commercial patents and scientific publications. Such indicators are below the average of those countries with similar economies. This performance must be partly due to its insuffi- cient R\&D efforts. Indeed, that situation is equally reflected in terms of R\&D investment as a proportion of the GDP with regard to a typical country with an economy and labor force of similar size. Mexico also lacks efficiency in its National System of Innovation (NIS), which is practically nonexistent. This is reflected in a low valuation of transformation of R\&D into commercial applications. This inefficiency is largely explained by the absence of cooperation between private companies and university researchers. Therefore, it is necessary to investigate the structural roots of Mexico's ineffective NIS more thoroughly, but this should not prevent continuing to experiment with policies that tackle the absence of innovation, which at present restricts the long-term prospects of its technological modernization (Lederman and William, 2003). Such circumstances offer extraordinary opportunities for the study of NIS in Mexico, i) by trying to explore the real existence of a NIS, ii) by defining and measuring the degree of development of each of its actors and elements, and iii) by describing the degree of dynamism developed by the NIS (if it exists) or to identify the emerging potential of a NIS.

\section{NIS and KBE Representative Approaches}

\section{National Innovation System Approaches}

A contribution for the development of NIS and RIS is the approach called "model of the environments" (Fernández and Castro, 2001). In this model, the authors state that practical experience and sociological studies of innovation (Callon, 1992) indicate that, although innovation "crystallizes" in the company, this is the result of multiple interactions between numerous and diverse agents. These heterogeneous agents can be grouped according to their function in the IS, in broad sets called "environments" (productive, technological, scientific, financial, etc.), that interact with one another, with the market and the public administrations throughout the innovative process.

Arnold and Kuhlman (2001) propose a NIS approach from a heuristic standpoint and not a merely regulatory model, trying to illustrate what is understood by an increasing number of analysts about NIS. In this model the authors define: the industrial system, the education and research system, the intermediary organizations, the political system, the demand and the framework conditions. This combination of different resources and institutional and organizational responsibilities under the same perspective make it possible:

1. to align the interactions between financing $R \& D$ industrially focused on the needs of innovation in the industry and the related infrastructure, 
2. to carry over the results of scientific research to applied R\&D across the intermediary organizations, and

3. to emphasize those conditions that facilitate or hinder the development of an innovative environment.

Fisher (2001) develops the NIS approach from a conceptual framework. The central idea of this approach falls to the fact that the economic performance of territories (countries or regions) not only depends on how the companies work, but also on how they interact with one another and with the public sector in the creation and dissemination of knowledge. Innovative companies operate inside an institutional context and they jointly depend on, contribute to and use an infrastructure of common knowledge. Systems that try to align the whole innovation process can expect to include four key elements (manufacturing sector, scientific, services and institutional) that the groups of actors integrated sharing some common characteristics and the institutions that govern the relations inside and between the groups. Finally, in order to describe and compare the IS, it is necessary to open the boxes of the subsystems, identify the constitutive elements and specify the relations between and within the subsystems that are important for innovative performance. The first resource of diversity between different systems, for example, may be the consequence of differences in the macroeconomic context, the quality of the information and the communication infrastructures.

Mytelka (2002) proposes a NIS based on the definitions developed by Nelson and Winter (1982), Lundvall (1992) and Nelson (1993), and maintain that the innovation approach system is an understanding of innovation as an interactive process in which enterprises interact with each other and are supported by institutions and a wide range of organizations that play a key role in bringing new products, new processes and new forms of organization into economic use. This approach emphasizes that i) the actor's competences, habits and practices with respect to three of the key elements that underlie an innovation process (linkages, investment and learning), also important in determining the nature and extensiveness of their interactions (Mytelka, 2000), ii) the proposal acknowledges the role of policies, whether tacit or explicit, in setting the parameters within which these actors make decisions about learning and innovation, iii) the habits, practices and institutions are learned behaviour patterns, marked by the historical specificities of a particular system and moment in time, and iv) it redirects attention towards the flows of knowledge and information that are at the heart of an innovation system, which is multidirectional and links a wider set of actors than those located along the value chain.

\section{Knowledge-Based Economies Approaches}

Knowledge Asset Methodology (KAM) points to the creation of skills in countries to take advantage of the new opportunities produced by the knowledge revolution and the effects of the development of knowledge dimensions in development strategies. This methodology consists of a set of 69 structural and qualitative variables, which can be used for benchmarking in the sense of "as an economy is compared with its neighbors, competitors, or countries which it wishes to imitate" (World Bank, 2002). The methodology's intention is "to identify the problems and opportunities of the different faces from a country, where it may be required to focus the attention of policies or future investments." The set of 69 variables serves as representations for the four areas that are considered most critical in the development of a knowledge-based economy: i) an economic and institutional system, ii) populations of citizens with education and skills, iii) a dynamic information infrastructure that ensures effective communications, and iv) an efficient IS of companies, research centers, universities, consultancies and other organizations to operate the global knowledge, to assimilate and to adapt it to local requirements and to generate new technology.

The Organisation for Economic Cooperation and Development (OECD) has developed several studies and reports related to the development of the knowledge-based economy (KBE). The Knowledge-based Economy (OECD, 1996) was an early attempt to compile statistical indicators about the KBE. It later published other studies related to the knowledgebased economy (OECD, 1999b) and the new economy (OECD, 2001). The OECD emphasizes that to understand the KBE performance, new economic concepts and measures are required that follow the phenomenon beyond conventional market transactions. In general, the OECD has suggested improving the $\mathrm{KBE}$ indicators in order to: i) measure the knowledge input, ii) measure the stocks and flows of knowledge, iii) measure the results of the knowledge, iv) measure the knowledge networks, and v) measure knowledge and learning.

The approach to knowledge-based economies (KBE) developed by APEC (APEC Economic Committee, 2000), aimed "to provide a useful analytical base to promote the effective use of knowledge, and the creation and dissemination of knowledge between APEC economies". This approach presents four dimensions that characterize the KBE, which are largely responsible for the economic development of some economies during recent decades: i) innovation and technological change, ii) development of human resources, iii) an efficient ICT infrastructure, and iv) an enterprise environment. APEC proposes 
a series of indicators based on their availability in each specific case study.

\section{Contributions of the Models for a NIS in Mexico}

Although Mexico can be considered as an intermediate country, there are still certain deficiencies and limitations that must be overcome. It can be affirmed that these problems must be resolved to be able to apply the NIS approach to Mexico. However, scientific and technological development does not wait, and Mexico must learn to overcome its problems whilst developing its innovative potential. This will help to increase the country's skills.

According to this analysis, the NIS approach is considered to be a suitable methodology to take into account if the aim is to strengthen the country's socioeconomic development. In this respect, the $\mathrm{KBE}$ model is considered the appropriate model to complement this NIS approach. Besides considering those missing elements, it considers the economy from a knowledge perspective, aiming at the development of the necessary skills to maintain the country's development.

With reference to the Oslo Manual (OECD, 2005), it is possible to affirm that the yield of an innovation process depends on four factors: i) regulating factors of the geographic area (structural elements of the process), ii) knowledge base of the society, iii) transfer factors of information and knowledge, and iv) dynamic factors of the innovation (organizational elements of the companies). These four factors constitute the elements that allow the creation and development of a NIS. This development causes an efficient innovative process in a determined socioeconomic area. Each one of these factors is represented by one or several actors who are, in fact, the agents who give coherence and consistency to the NIS. Therefore, the effectiveness of the innovative and creative processes of knowledge will depend on the effectiveness with which these factors or mechanisms are fulfilled.

\section{Proposed Framework for a NIS in Mexico}

The proposal considers that the frameworks (economic, institutional, sociocultural, and information and communication) surround all NIS like a determining factor for the development of a strong economy, because it is from where the first processes of knowledge development are generated and sustained (see Fig 1). However, the most important elements of the NIS (environments) are located within the same system, because it is within this where most of the generated knowledge is capitalized. Even so, although one of the most important beneficiaries of knowledge creation are companies, such benefits are generally reflected in society because they are the sources of product generation, improved services, employment and economic and social development.

Therefore, if some NIS elements, both the framework and the scope, are avoided, this could entail an obstruction and a backward movement of the benefits achieved throughout its evolution, without mentioning the negative impact on the economy and society.

\section{System Framework}

a) Economic framework. It gives a general description of the country's economic situation (i.e. GDP, inflation, exchange rate, interest rates, etc.), and other indicators that usually have an important effect on the country's economic performance (i.e. index of competitiveness, foreign investment, spending power, financing, etc.).

From the knowledge perspective, the economic framework is the result of taking advantage of the creation, transformation and dissemination of knowledge throughout the NIS. It reflects the appropriate operation of all actors in the same system, and acts as a stimulator for the innovative activities that produce economic capital and develop these activities. 


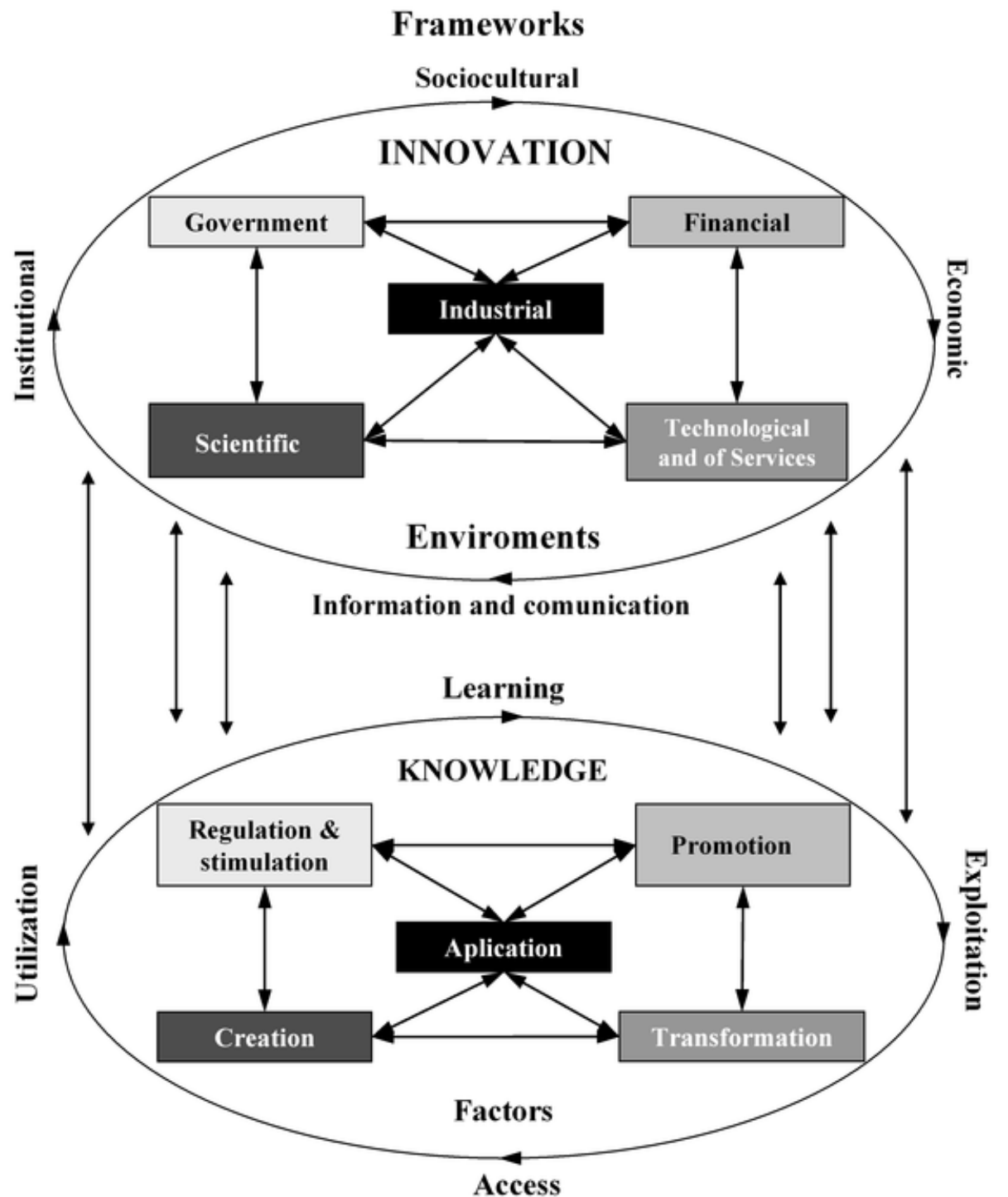

Fig. 1: National System of Innovation

b) Institutional framework. It refers to one of the key elements for maintaining the development strategies of the most competitive countries, which is the creation of institutions (both public and private), whose goal is to contribute to the best operation of the whole economic system. However, an excessive regulatory framework and red tape to solve the legal problems stimulate corruption, affecting companies' competitiveness and growth capacity.

From a knowledge standpoint, the institutional framework will provide the rules to manage knowledge for all players in the NIS. Thus, efficient institutions will use and take advantage of available resources for innovative activities. The results obtained from the remaining frameworks reflect the good or bad management of the available resources for innovative activities and knowledge dissemination; these are delimited by the institutional framework. c) Sociocultural framework. It considerably contributes to the performance and evolution of the NIS, through common practices that later become customs, and largely determines what finally becomes culture. Thus, for example, education creates the necessary conditions to generate a sense of the fairness, justice, respect and social responsibility. These conditions are key for the social and economic life of a nation as well as for its competitiveness. However, a high education level is not guarantee of greater productivity.

From a knowledge standpoint, the sociocultural framework will create the sufficient and necessary basis so that the knowledge generated within the NIS can be absorbed by that environment. Thus, at a national level, the absorption capacity is created in such way that the knowledge can be learned by organizations and people. This learning process has significant positive effects over the entire NIS, which is 
possible because this framework specifies the system's creative and innovative potential.

d) Information and Communication framework. Translated into an available infrastructure, it is an important factor of national development, because the location of the companies and access to information establish certain restrictions to socioeconomic development. An example of this are the restrictions in time efficiency, transport costs and the service level that the companies will be able to render from the local level up to the international level.

From a knowledge standpoint, the Information and Communication framework mainly specifies the general public's facilities to access information and knowledge. The most developed economies use this framework to increase knowledge flow, allowing its transfer in a fast and effective way. However, in undeveloped countries like Mexico, the effectiveness could be limited if the sociocultural framework is not appropriately developed.

\section{System Environment}

a) Business environment. It includes all those companies that are within the NIS. These companies are not only limited to large and high technology companies (public and private) that generate goods and services, but it includes all those companies that constitute the critical mass (micro, small, medium and large) of the entire NIS and those in which acquired knowledge is applied.

From a knowledge standpoint, in the business environment firms have the primary responsibility for applying the transformed knowledge and validating its transformation. Such validation is used as a filter for the goods and services created through the generation of both economic benefits for the firms and social benefits. It covers a set of needs that are not satisfied in general users. However, its application will not be limited to the creation of such knowledgebased goods and services. The application will be limited by the knowledge absorption capacity in companies and the development level of each NIS framework.

b) Scientific environment. It includes the universities and the public research institutions through which the knowledge is created. It constitutes one of the crucial elements of the NIS. However, the facilities or limitations of entailment with other system elements can inhibit their development to a greater extent, making this area a mere supplier of human resources rather than a knowledge supplier.

From a knowledge standpoint, the main role of the scientific environment is the creation of knowledge by its incorporation as a human resource, or as the developed projects in Science and Technology. Therefore, this environment is the key for the suitable performance of the NIS. In this environment, the critical mass of knowledge is created; this knowledge is used to sustain the scientific and technological development of a country. However, innovation is not only present in the scientific environment, other system elements can develop another kind of innovation (non-technological innovations).

c) Technological and Service environment. It is constituted by those companies oriented towards the operation of the R\&D results developed in the scientific field, with the purpose of reinforcing the absorption capacity of the existing companies and promoting the creation of the associated companies and companies created within universities.

From a knowledge standpoint, companies transform scientific knowledge into applied knowledge. For example, applications that can be used for commercial purposes are integrated in different products and services. Due to the wide range of services offered by the companies as intermediary organizations, it makes them move through different areas that are not necessarily scientific. Technology managers, for example, can usually provide services from mere trading in the commercial transaction for the acquisition of a technological product, through coaching and training, to developing a specific application for a company.

d) Government environment. It plays a crucial role within the NIS because the economic development of the country largely depends on this. It also develops a regulating and stimulating role of the innovative activities aimed at creating knowledge within the NIS, when creating S\&T policies and programs that promote their development within the institutions and the companies that are in the NIS.

From a knowledge standpoint, the government has a key role. It plays a regulating and stimulating role for innovative activities that tend to create knowledge in the NIS. The government has the responsibility of creating Science and Technology policies and programs that foster their development in the NIS institutions and companies. Policies and programs allow the agents to develop those innovative activities that produce knowledge and economic and social benefits.

e) Financing environment. It includes all those organizations (private banks, non-profit private organizations, etc.) responsible for providing economic resources to companies to develop their innovative activities. Nevertheless, this is not always true, since it is usually a function that is shared between governmental and private organizations. 
From a knowledge standpoint, the financial environment is responsible for promoting innovative activities. This is done by providing access to businesses in order to finance technology-oriented development (public and private), through the different programs and funding schemes developed by both the government and private companies. However, this environment depends to a great extent on developing appropriate policies. Such policies must aim to promote and facilitate access to finance for businesses. In addition, this strategy helps to encourage companies to invest in research and development.

Given the present situation in Mexico relating to science, technology and innovation, it is of interest to consider only those indicators that are generally available in the country. Some of the proposed indicators are presented below (see Fig 2).

\begin{tabular}{|c|c|c|c|}
\hline & $\begin{array}{c}\text { NIS } \\
\text { Element }\end{array}$ & $\begin{array}{l}\text { Know ledge } \\
\text { Factor }\end{array}$ & Indicator \\
\hline \multicolumn{4}{|c|}{ Framew ork } \\
\hline & Economic & Exploitation & $\begin{array}{l}\text { GDP, inflation, exchange rates, interest rates, rate of unem } p \text { loym ent } \\
\text { m inim um } w \text { age, foreign investm entG D } P \text {, indicator of com petitiveness. }\end{array}$ \\
\hline b) & In atitutional & 0 tillizacion & 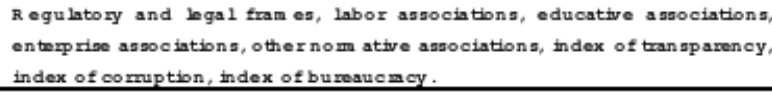 \\
\hline a) & Sociocultural & Leaming & $\mathrm{E}$ ducative, labor, of cred it, cu laural, goc in 1 ind da ators. \\
\hline d) & $\begin{array}{l}\text { Informaion } s \\
\text { Comunication }\end{array}$ & A cosess & $\begin{array}{l}\text { PC's per } 1000 \text { inhab., phones per } 1000 \text { inhab., intemet acoess per } 1000 \\
\text { inhab., num ber of PC per gchoole, num ber of librarieg per } 1000 \text { inhab. }\end{array}$ \\
\hline \multicolumn{4}{|c|}{ Environm ent } \\
\hline a) & Soientific & C reation & 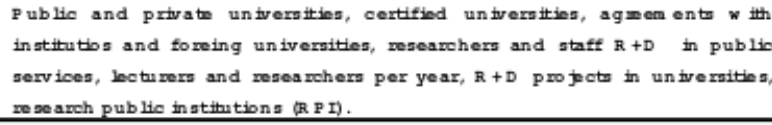 \\
\hline b) & B usiness & A pliation & $\begin{array}{l}\text { Foreign com panies per sector, national com pan ies per sector, ocupied } \\
\text { population per industrial sectors, explotation incom es per industrial sectors, } \\
\text { university population ocup ied, exportations and in portations per sectors. }\end{array}$ \\
\hline a) & $\begin{array}{l}\text { Technological } \\
\text { and Services }\end{array}$ & Tranafom ation & N ational reg inter of in atithitiong and com panieg of $8 \mathrm{G} T$, ingtitutional fund. \\
\hline & G ovemn ent & $\begin{array}{c}\text { Regulation \& } \\
\text { stimulation } \\
\end{array}$ & 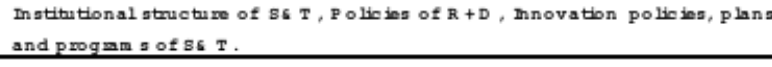 \\
\hline & $\mathbf{F}$ inancin 1 & P rom otion & 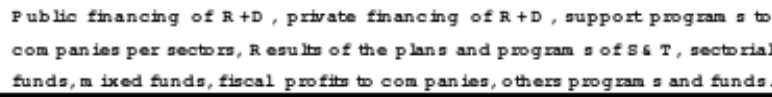 \\
\hline
\end{tabular}

Fig. 2: Proposed Indicators in Mexico

\section{Advantages of the Proposal}

The results obtained from the review of the different NIS approaches, the KBE models and the current situation of innovation in Mexico, allow the development of the new NIS approach to Mexico from a systemic point of view. Since a large part of the previously analyzed approaches generally use similar indicators (i.e. patents, publications, R\&D expenditure, etc.), the main issue of the proposed approach (to stand out) is that it takes into account those indicators that allow the reduction and measurement of the distances with regard to other nations in relation to development levels. Thus, the use of the different existing frameworks (cultural, social, institutional, political and legal) is emphasized, since these determine the context in which one tries to apply the proposed NIS approach. Therefore, the scope of the proposal covers the ratification of those elements (and their relations) that integrate the NIS approach proposed, in order to evaluate their presence with regard to this, in addition to the framework presented previously.

\section{Conclusions}

In accordance with the first findings related to the application of the approach presented in the proposed NIS, an attempt has been made to show an initial view of the status of science, technology and innovation in Mexico, in such a way that experiences from other countries are used as a benchmark to evaluate the approach performance. The approach reformulation makes it possible to correct those gaps that were not considered during its initial development, aligning the proposed approach with reality and with the international environment.

Although, it is desirable that the application of the NIS approach is evaluated according to the results reached throughout its evolution, the above-mentioned evaluation is related to the analysis of the results obtained during its application. Thus, the status of science, technology and innovation in Mexico, as well as the proposed solutions and the context of this new approach within the international environment, can be used as reference for other countries with similar characteristics.

The results expected from applying the proposed approach include: i) evaluating the existing elements 
compared with the proposed model, ii) determining the degree of integration of the existing NIS, iii) quantifying the results of its management as a whole, from a systemic approach, iv) detecting the obstacles and restrictions in the different NIS elements and levels and v) constructing a decision-making support base for the establishment of R\&D and innovation policies and strategies. All with the aim of defining and proposing a series of recommendations that allows the form of a NIS for Mexico to be delimited.

\section{References}

APEC Economic Committee. Towards knowledge-based economies. Technical report. Asia-Pacific Economic Cooperation, 2000.

ABS. Measuring a Knowledge-based Economy and Society - An Australian Framework. Discussion Paper. Australia, 2002.

Arnold, E. and Kuhlman, S. Rcn in the Norwegian research and innovation system. Technical Report $\mathrm{n}^{\circ} 12$. Norway: Research Council of Norway, 2001.

Callon, M. Recherche et innovation en France. Paris: Centre de Sociologie de l'Innovation, 1992.

Casas, R., deGortari, R. and Santos, M. "The building of knowledge spaces in Mexico: a regional approach to networking". Research Policy 29 (2000): 225.

CONACYT. Programa Especial de Ciencia y Tecnología 2001-2006. México: Consejo Nacional de Ciencia y Tecnología, 2001.

Informe General del Estado de la Ciencia y la Tecnología en México, México: Consejo Nacional de Ciencia y Tecnología, 2006.

Davis, Ch. "Integración económica de América del Norte y la política de innovación en Canadá". In Ciencia y Tecnología, y Tratado de Libre Comecio. México: CONACYT, 1991.

Interview within the framework of First International Workshop in Policy and Technological Modernization. México: TecnoIndustria, 1992.

DTI. Our competitive future: Building the knowledge driven economy, Technical report, Department of Trade and Industry. London, 1998.

Fernández, I. and Castro, E. Innovación y Sistemas de Innovación, Valencia: Universidad Politécnica de Valencia. 2001.

Fisher, M. "Innovation, knowledge creation and systems of innovation". The Annals of Regional Science 35, 2 (2001): 199.

Freeman, C. Technology Policy and Economic Performance. London: Pinter, 1987.

Hidalgo, A. Innovation Management and the Knowledge-Driven Economy. Brussels-Luxembourg: European Comisión, 2004.

Hill, R. and Wonnacott, R.J. Free Trade with Mexico. Commentary. Canada: Howe Institute, 1991.

INEGI and CONACYT. Encuesta Na cional sobre Innovación en los Sectores Manufactureros y de Servicios 2001. México: INEGI, 2001.

Lederman, D. and William, M. Innovación en México. Oficina del Economista en Jefe para América Latina y el Caribe. Washington DC: World Bank, 2003.

Lundvall, B. National Systems of Innovation: towards a theory of innovation and interactive learning. London: Pinter Publisers, 1992.

Mortensen, J., Eustace, C. and Lannoo, K. "Intangibles in the european economy". CEPS Workshop on intangibles in the European economy. Brussels, 1997.

Mytelka, L. "Competition, innovation and competitiveness: A framework for analysis". In Competition, Innovation and Competitiveness in developing countries. Paris: OECD, 2000.

Mytelka, L. and Smith, K. "Policy learning and innovation theory: an interactive and co-evolving process". Research Policy 31 (2002): 1467.

Nelson, R. and Winter, S. An Evolutionary Theory of Economic Change. Cambridge MA: Harvard University Press, 1982. Nelson, R. National Innovation Systems: a comparative analysis. London: Oxford University Press, 1993.

OECD. The Knowledge-based Economy. Technical report. Paris: OECD, 1996. Managing National Innovation Systems. Technical report, Paris: OECD, 1999.

The Knowledge-based Economy: A Set of Facts and Figures. Paris: OECD, 1999b.

The New Economy: Beyond the Hype. Final Report on the OECD Growth Project. Paris: OECD, 2001.

Oslo Manual. Guidelines for Collecting and Interpreting Innovation Data. Paris: OECD, 2005.

Patel, P. and Pavitt, K, "The nature and economic importance of national innovation systems", STI Review 14, OECD, 1994.

World Bank. Programme on Knowledge for Development, Knowledge Assessment Methodology and Scorecards. Washingnton DC: World Bank, 2002. 


\section{About the Authors}

Victor Helios Feria

Victor Feria was born in 1971, at Mexico. He studied Chemical Engineering at Universidad Veracruzana, Mexico, obtaining a bachelor degree in 1995. In 2000, he was graduated in Project Management at Project Management Institute, Mexico. From 1997 to 2003, he was working as Project Manager focused on the ERP systems at Mexico. Since 2004, he is Phd Student in the Department of Engineering Projects at the Polytechnic University of Valencia, Spain. In 2005, he obtained the postgraduate in Engineering Projects and Innovation at Polytechnic University of Valencia (Department of Engineering Projects), Spain. His scientific activity is focused mainly in the fields of National Innovation Systems, Linkage among Universities and Industries, KnowledgeBased Economies, and Knowledge Transference.

\section{Dr. Antonio Hidalgo}

Antonio Hidalgo is Professor of Technology Strategy and Director of the Research Group of Innovation, IPR and Technology Policy, and Director of the Master and Doctorate Programme in MoT, Universidad Politécnica de Madrid, Spain. He received his PhD in Industrial Engineering from the Universidad Politécnica de Madrid in 1992. He has acted as expert to the European Commission as technology consultant in the European Innovation Monitoring System. His works have appeared in Production, Planning and Control Journal, Journal of Intelligent Manufacturing, Journal of Technology Transfer, International Journal of Product Development, International Journal of Entrepreneurship and Innovation Management, and R\&D Management. He teaches technology strategy to MBA/PhD students and executives. 

EDITORS

Bill Cope, University of Illinois, Urbana-Champaign, USA.

Mary Kalantzis, University of Illinois, Urbana-Champaign, USA.

\section{EDITORIAL ADVISORY BOARD}

Darin Barney, McGill University, Montreal, Quebec, Canada.

Marcus Breen, Northeastern University, Boston, USA.

G.K. Chadha, Jawahrlal Nehru University, India.

Simon Cooper, Monash University, Australia.

Bill Dutton, University of Oxford, United Kingdom.

Amareswar Galla, The University of Queensland, Australia.

David Hakken, University of Indiana, Bloomington, Indiana, USA.

Michele Knobel, Montclair State University, New Jersey, USA.

Jeannette Shaffer, Edtech Leaders, VA, USA.

Ravi S. Sharma, Nanyang Technological University, Singapore.

Robin Stanton, Australian National University, Canberra, Australia.

Telle Whitney, Anita Borg Institute for Women and Technology.

Please visit the Journal website at http://www.Technology-Journal.com for further information about the Journal or to subscribe. 


\title{
THE UNIVERSITY PRESS JOURNALS
}

\author{
International Journal of the Arts in Society \\ Creates a space for dialogue on innovative theories and practices in the arts, and their inter-relationships with society. \\ ISSN: 1833-1866 \\ http://www.Arts-Journal.com
}

International Journal of the Book

Explores the past, present and future of books, publishing, libraries, information, literacy and learning in the information society. ISSN: 1447-9567

http://www.Book-Journal.com

Design Principles and Practices: An International Journal

Examines the meaning and purpose of 'design' while also speaking in grounded ways about the task of design and the use of designed artefacts and processes. ISSN: 1833-1874 http://www.Design-Journal.com

International Journal of Diversity in Organisations, Communities and Nations

Provides a forum for discussion and builds a body of knowledge on the forms and dynamics of difference and diversity. ISSN: $1447-9583$

http://www.Diversity-Journal.com

International Journal of Environmental, Cultural, Economic and Social Sustainability

Draws from the various fields and perspectives through which we can address fundamental questions of sustainability. ISSN: 1832-2077

http://www.Sustainability-Journal.com

Global Studies Journal

Maps and interprets new trends and patterns in globalization. ISSN 1835-4432

http://www.GlobalStudiesJournal.com

International Journal of the Humanities

Discusses the role of the humanities in contemplating the future and the human, in an era otherwise dominated by scientific, technical and economic rationalisms. ISSN: 1447-9559

http://www. Humanities-Journal.com

International Journal of the Inclusive Museum

Addresses the key question: How can the institution of the museum become more inclusive? ISSN 1835-2014 http://www.Museum-Journal.com

International Journal of Interdisciplinary Social Sciences

Discusses disciplinary and interdisciplinary approaches to knowledge creation within and across the various social sciences and between the social, natural and applied sciences.

ISSN: 1833-1882

http://www.Socialsciences-Journal.com

International Journal of Knowledge, Culture and Change Management

Creates a space for discussion of the nature and future of organisations, in all their forms and manifestations.

ISSN: $1447-9575$

http://www.Management-Journal.com

International Journal of Learning

Sets out to foster inquiry, invite dialogue and build a body of knowledge on the nature and future of learning.

ISSN: $1447-9540$

http://www.Learning-Journal.com

International Journal of Technology, Knowledge and Society

Focuses on a range of critically important themes in the various fields that address the complex and subtle relationships between technology, knowledge and society. ISSN: 1832-3669 http://www.Technology-Journal.com

Journal of the World Universities Forum

Explores the meaning and purpose of the academy in times of striking social transformation. ISSN 1835-2030

http://www.Universities-Journal.com

\author{
FOR SUBSCRIPTION INFORMATION, PLEASE CONTACT \\ subscriptions@commonground.com.au
}

